\title{
Patient web portals, disease management, and primary prevention
}

This article was published in the following Dove Press journal:

Risk Management and Healthcare Policy

7 April 2017

Number of times this article has been viewed

\author{
Steven S Coughlin' \\ Judith J Prochaska ${ }^{2}$ \\ Lovoria B Williams ${ }^{3}$ \\ Gina M Besenyi' \\ Vahé Heboyan' \\ D Stephen Goggans ${ }^{4}$ \\ Wonsuk Yoo ${ }^{5}$ \\ Gianluca De Leo' \\ 'Department of Clinical and Digital \\ Health Sciences, College of Allied \\ Health Sciences, Augusta University, \\ Augusta, GA, ${ }^{2}$ Department of \\ Medicine, Stanford Prevention \\ Research Center, Stanford University, \\ Stanford, CA, ${ }^{3}$ Department of \\ Biobehavioral Nursing, College \\ of Nursing, Augusta University, \\ ${ }^{4}$ Department of Public Health, East \\ Central Health District, ${ }^{5}$ nstitute of \\ Public and Preventive Health, Augusta \\ University, Augusta, GA, USA
}

Background: Efforts aimed at health care reform and continued advances in information technologies have prompted interest among providers and researchers in patient web portals. Patient web portals are password-protected online websites that offer the patients 24 -hour access to personal health information from anywhere with an Internet connection.

Methods: This article, which is based upon bibliographic searches in PubMed, reviews important developments in web portals for primary and secondary disease prevention, including patient web portals tethered to electronic medical records, disease-specific portals, health disparities, and health-related community web portals.

Results: Although findings have not been uniformly positive, several studies of the effectiveness of health care system patient portals in chronic disease management have shown promising results with regard to patient outcomes. Patient web portals have also shown promising results in increasing adherence with screening recommendations. Racial and ethnic minorities, younger persons, and patients who are less educated or have lower health literacy have been found to be less likely to use patient portals.

Conclusion: Additional studies are needed of the utility and effectiveness of different elements of web portals for different patient populations. This should include additional diseases and health topics such as smoking cessation and weight management.

Keywords: chronic diseases, diabetes, electronic health record, health disparities, hypertension, health information technology, immunization, patient web portals, screening

\section{Introduction}

Web portals have increasingly become a ubiquitous part of modern life. They bring together information from different sources in a uniform way and allow organizations and institutions to provide a more consistent look and feel for multiple applications, content, and information from databases. ${ }^{1}$ Users are presented with a single web page that can bring together content from a number of systems or servers. The content can be displayed on secure personal computers, tablets, and smartphones. Web portals can include multimedia applications for social networking and digital images (e.g., photographs, X-rays, documents such as publications) including the material not indexed by standard search engines. Examples include government web portals such as web portals used by public and private academic institutions, the portals used by corporations and the business sector, and patient web portals provided by health care organizations. ${ }^{1,2}$

Efforts aimed at health care reform and continued advances in information technologies have increased interest among providers and researchers in patient web portals.
Correspondence: Steven S Coughlin Department of Clinical and Digital Health Sciences, College of Allied Health

Sciences, Augusta University, I I 20

I5th Street, EC-4324, Augusta, GA 30912 , USA

Tel +l 706 72I 4643

Email scoughlin@augusta.edu
Risk Management and Healthcare Policy 20I 7: 10 33-40

33

Dovepress if in

(c) (c) 2017 Coughlin et al. This work is published and licensed by Dove Medical Press Limited. The full terms of this license are available at https://www.dovepress.com/terms. cc) php and incorporate the Creative Commons Attribution - Non Commercial (unported, v3.0) License (http://creativecommons.org/licenses/lyy-nc/3.0/). By accessing the work you hereby accept the Terms. Non-commercial uses of the work are permitted without any further permission from Dove Medical Press Limited, provided the work is properly attributed. For permission for commercial use of this work, please see paragraphs 4.2 and 5 of our Terms (https://www.dovepress.com/terms.php). 
Patient portals are web-based, patient-centered health care information systems linked to a patient's electronic medical record. ${ }^{2,3}$ A patient portal is a password-protected online website that offers patients 24-hour access to personal health information from anywhere with an Internet connection. ${ }^{2,3}$ Patient portals were first introduced in the USA in the late 1990s, partly in response to stipulations in the Health Insurance Portability and Accountability Act of 1996 that patients be able to see and obtain copies of their medical records and request amendments to those records. In 2015, $50 \%$ of US hospitals and $40 \%$ of US physicians had a secure patient portal in place. ${ }^{4}$ Another important development is the meaningful use criteria of the Centers for Medicare and Medicaid Services electronic health records incentive program, which mandates that a clinical summary be provided to the patient after each visit, with the ability for secure messaging between the patient and the provider and the ability to view, download, and transmit personal health record data, patient-specific education, patient reminders for preventive services, and medication reconciliation. ${ }^{5}$ Now patients can view health information such as doctor visits, discharge summaries, medications, immunizations, lab results, and results of X-rays and other diagnostic tests. ${ }^{6,7}$ Many patient portals also allow patients to request prescription refills, schedule appointments, exchange email with their health care providers, and view educational materials. ${ }^{2}$ Health care stakeholders view patient portals and parallel advances in e-health, such as personal health records and electronic medical records, as an opportunity to leverage information technology to support patient self-management and improved patient-provider communication between office visits. ${ }^{8}{ }^{89}$ Over the past decade, the number of peer-reviewed publications on patient portals has increased exponentially.

Previous reviews on the effectiveness of web portals in improving patient outcomes omit recently published studies on topics such as disease prevention, health disparities, and community web portals and health ${ }^{3,10}$ or the focus was on studies of web portals for a single disease. ${ }^{11}$ Our aim was to review the evidence on patient web portals for disease management, disease-specific portals, and disease prevention and to examine the disparities in portal use.

\section{Methods}

The present review is based on bibliographic searches in PubMed and relevant search terms. Articles published in English from 1993 to November 2016 were identified using the following MeSH search terms and Boolean algebra commands: (web portals or patient web portals) and health. The searches were not limited to words appearing in the title of an article. The searches were not limited to studies in a particular country or geographic region of the world. Information obtained from bibliographic searches (title and topic of article, information in abstract, study design, and keywords) was used to determine whether to retain each article identified in this way. Only studies with a randomized controlled trial or comparative observational study design (e.g., cohort study, cross-sectional survey) were included. In addition, the references of review articles were reviewed., 2,3,10,11

A total of 620 article citations were identified in the bibliographic searches. After screening the abstracts or full texts of these articles and reviewing the references of previous review articles, ${ }^{2,3,10,11}$ a total of 35 studies of the impact of patient web portals on disease management or disease prevention were identified. This included 13 studies of web portals tethered to electronic medical records, 12 disease-specific web portals, 6 web portals for specific types of patients, and 4 web portals addressing preventive services.

\section{Results}

With respect to web portals tethered to electronic medical records and used for disease management, several of these studies have shown promising results, ${ }^{12-21}$ although findings have not been uniformly positive. ${ }^{22}$ Wade-Vuturo et al ${ }^{12}$ examined the efficacy of web portal use among 54 adult patients with type 2 diabetes seen at an academic medical center in Nashville, TN. Greater self-reported use of secure messaging between patient and clinician was significantly associated with the patient's glycemic control $(p=0.04)$. Self-reported use of the portal to review laboratory results or view their personal health information was not associated with glycemic control. ${ }^{12}$ In a retrospective cohort study of veterans with diabetes registered for the My Health $e$ Vet patient portal, Shimada et $\mathrm{al}^{13}$ evaluated the association between sustained use (over 2 years) of web-based prescription refill and secure messaging and laboratory tests used in the management of type 2 diabetes. Patients with uncontrolled hemoglobin A 1c (HbAlc) at baseline who used secure messaging were more likely than nonusers to achieve glycemic control, with adjustment for age, sex, and eligibility for free care (odds ratio [OR] $=1.24,95 \%$ confidence interval [CI] 1.14-1.34). Patients with uncontrolled blood pressure at baseline who used web-based refills were more likely than nonusers to achieve control at follow-up with 2 more years of web-based refill use (OR=1.08, 95\% CI 1.02-1.14). Studies of Group Health Cooperative diabetes patients found significant associations between the use of secure messaging 
and improvements in glycemic testing and control. ${ }^{14,18}$ Association of portal use and improvements in cholesterol have also been observed among Kaiser Permanente patients with diabetes and hypertension. ${ }^{15}$ In a matched-control analysis, secure patient-physician messaging was associated with improved performance $(p<0.0001)$ in HbA1c screening and control, low density lipoprotein-cholesterol screening and control, retinopathy screening, and nephropathy screening of $2.4 \%-6.5 \%$. It was also associated with improved performance in blood pressure control among patients with diabetes $(p<0.001)$ and with blood pressure control among members with hypertension alone $(p=0.002)$. Tenforde et al examined the use of electronic personal health records by adult diabetes patients seen at the Cleveland Clinic $(\mathrm{N}=10,746)$. Compared to nonusers, personal health record users had better diabetes quality measure profiles. The adjusted OR of HbA1c testing was $2.06(p<0.01)$. Among personal health record users, increasing number of login days was not associated with more favorable diabetes quality measure profiles, suggesting that better diabetes profiles among users are due to higher level of engagement with their health rather than personal health record use itself. ${ }^{16}$ Green et al ${ }^{17}$ conducted a cluster randomized controlled trial to examine the effectiveness of home blood pressure monitoring, web communication, and pharmacist care (i.e., clarifying antihypertensive medications) on hypertension control. Of 778 participants seen by Group Health in Washington state and Idaho, there was a nonsignificant increase in the percentage of patients with controlled blood pressure among the patients assigned to the home blood pressure monitoring and web training only group, compared with those under usual care (36\% vs. $31 \%, p=0.21)$. Adding web-based pharmacist care to home blood pressure monitoring and web training significantly increased the percentage of patients with controlled blood pressure (56\%), compared with those under usual care $(p<0.001)$. Wagner et $\mathrm{al}^{23}$ conducted a 9-month cluster randomized trial to examine the effectiveness of electronic personal health record use on hypertension control among 453 patients seen at two ambulatory care clinics in Greenville, SC. Personal health record use was not related to systolic blood pressure $(p=0.617)$, diastolic blood pressure $(p=0.287)$, or medical utilization. ${ }^{23}$ In a retrospective cohort study of primary care patients at an academic medical center who had a new diagnosis of hypertension, portal users were found to be more likely than nonusers to achieve blood pressure control (hazard ratio $=1.24$, 95\% CI 1.06-1.45). ${ }^{19}$ Ross et al ${ }^{20}$ conducted a randomized controlled trial to examine the effectiveness of a web-based online medical record with electronic communication capabilities (i.e., secure messaging between patient and clinician) in a specialty practice for patients with congestive heart failure $(\mathrm{N}=107)$. Surveys assessing patient adherence with treatment and health status were conducted at baseline, 6 months, and 12 months. At 12 months, the intervention group was superior in general adherence $(p=0.01)$. The intervention group had more emergency department visits (20 vs. 8, $p=0.03$ ), but these visits were not temporally related to use of the online medical record. In a cross-sectional analysis of data from the Veterans Aging Cohort Study, McInnes et $\mathrm{al}^{21}$ evaluated whether patient electronic personal health record use was associated with antiretroviral medication adherence among HIV-positive veterans $(\mathrm{N}=1,871)$. Patient use of their electronic personal health record was associated with $\geq 90 \%$ adherence after controlling for sociodemographic variables.

Patient portals have also shown promising results for mental health outcomes. In a randomized controlled trial conducted in nine primary care clinics in Washington state, Simon et $\mathrm{al}^{22}$ evaluated the effectiveness of a depression care management program delivered by online messaging through an electronic medical record. Two hundred and eight patients starting antidepressant treatment for depression were randomized to either usual primary care treatment or primary care supported by online care management by a psychiatric nurse. After 5 months, patients offered the program had higher rates of antidepressant adherence ( $81 \%$ vs. $61 \%, p=0.001)$ and lower symptoms checklist depression scores $(p=0.043)$. Kipping et $\mathrm{al}^{24}$ evaluated a web portal offered to patients at a mental health care facility. Users had web access to view parts of their electronic medical record, view upcoming appointments, and communicate with their health care provider. A subset of users $(n=91)$ completed online surveys at baseline and at follow-up ( 6 and 10 months). Among patients who used the portal, a measure of mental health recovery improved from baseline to follow-up $(p=0.01)$. Portal users were more likely to attend an appointment and less likely to request information over the follow-up period.

\section{Web portals for specific diseases and patient populations}

Web portals have also been developed for patients with specific diseases. These include portals for patients with diabetes, ${ }^{25-31} \mathrm{COPD},{ }^{32}$ asthma, ${ }^{33}$ breast cancer, ${ }^{34}$ attention-deficit/ hyperactivity disorder, ${ }^{35}$ and schizophrenia. ${ }^{36}$ Web portals have also been developed to meet the needs of particular patient populations, including pediatric patients and their guardians, ${ }^{35,37,38}$ maternity patients, ${ }^{39}$ patients receiving in vitro fertilization, ${ }^{40}$ and older adults. ${ }^{41}$ The wide variability 
in web portals for specific disease and patient populations, including the specific features that they offer, the outcomes evaluated, and whether the information technology resources were combined with a case management intervention, increases the difficulty of making general statements about their usefulness for disease management or alleviating symptoms. Future research should explore how individual and various combinations of web portal elements support underlying behavioral change and disease management and prevention mechanisms.

\section{Web portals and disease prevention}

Web portals have also been developed for preventive care. Krist et $\mathrm{al}^{42}$ conducted a randomized controlled trial of the effectiveness of an interactive preventive health record in eight primary care practices in Northern Virginia. The preventive health record provided the patients access to their electronic health record used by their clinician (including the test results), enabled them to discover inaccuracies in their medical records, assessed their needs by applying evidencebased guidelines and incorporating personal medical data to derive individualized recommendations, and linked guidance with personalized evidence-based educational resources and decision aids, community services, logistical details, and reminder systems. The preventive services of interest were colorectal, breast, and cervical cancer screening; hypertension, hypercholesterolemia, abdominal aortic aneurysm, and diabetes screening; chlamydia screening; osteoporosis screening; aspirin chemoprophylaxis use; tetanus, influenza, and pneumococcal immunization; and smoking cessation, dietary, exercise, and weight loss counseling. A total of 4,500 patients were randomly selected to receive a mailed invitation to use the interactive preventive health record or to receive usual care. At 4 and 16 months, 229 (10.2\%) and 378 (16.8\%) of the invited patients used the interactive preventive health record. ${ }^{42}$ The proportion of patients up-to-date with all ageand sex-appropriate services increased between baseline and 16 months by $3.8 \%$ among intervention patients (from $11.4 \%$ to $15.2 \%, p<0.001$ ) and by $1.5 \%$ among control patients (from $11.1 \%$ to $12.6 \%, p=0.07)$, with a difference of $2.3 \%(p=0.05)$. Wright et $\mathrm{al}^{43}$ conducted a cluster randomized controlled trial of the effectiveness of health maintenance reminders provided directly to patients through an electronic personal health record. A total of 3,979 patients seen at eleven primary care practices in Boston, MA, were enrolled in the trial. Patients in the intervention arm received health maintenance reminders through a secure personal health record e-Journal, which allowed them to review and update health maintenance and family history information. Patients in the control arm received access to an e-Journal that allowed them to input and review information related to medications, allergies, and diabetes management. Patients in the intervention arm were significantly more likely to receive mammography $(48.6 \%$ vs. $29.5 \%, p=0.006)$ and influenza vaccinations $(22.0 \%$ vs. $14.0 \%, p=0.018$ ). No significant improvement was observed in the rates of other screenings (bone density, cholesterol, Pap smear, Pneumovax).

Kaiser Permanente Southern California added the Online Personal Action Plan (oPAP) to the member web portal to provide members with information about disease prevention, health promotion, and care gaps. ${ }^{44} \mathrm{~A}$ study conducted by Henry et $\mathrm{a}^{44}$ described Kaiser Permanente Southern California users who use oPAP and how members use oPAP to close five different care gaps: HbA1c testing, pneumonia vaccination, and three cancer screenings. Care gap closure rates for oPAP users and members not registered on the patient portal between December 2014 and March 2015 were compared. A total of 838,638 cases (mean age 49.5 years; $40.4 \%$ oPAP users) were examined. After adjustment for potential confounding variables, oPAP access was associated with a somewhat greater likelihood of care gap closure within 90 days for HBA1c testing and breast, cervical, and colorectal cancer screening among eligible members. ${ }^{44}$

Nagykaldi et $\mathrm{al}^{45}$ developed a wellness portal for patientcentered preventive care, examined its feasibility and acceptability in a pilot study in two primary care practices in Oklahoma, and subsequently conducted a 12-month cluster randomized controlled trial in eight clinician practices to study its impact on service delivery. About $90 \%$ of the patients in the pilot study found the portal easy to use, $83 \%$ judged it a valuable resource, and $80 \%$ indicated it facilitated their participation in preventive care. The cluster randomized controlled trial included 422 adults of age 40-75 years and parents of 116 children aged 2-5 years. Seventy-three percent of patients used the portal during the study. Participants' perception of patient-centeredness of care increased significantly in the web portal group compared with control $(p=0.037)$. A greater proportion of portal users received all recommended preventive services $(84.4 \%$ intervention vs. $67.6 \%$ control, $p<0.0001)$; took low-dose aspirin, if indicated (78.6\% intervention vs. 52.3\% control, $p<0.0001)$; and received Pneumovax because of chronic health conditions $(82.5 \%$ vs. $53.9 \%, p<0.0001)$ and age $(86.3 \%$ vs. $44.6 \%$, $p<0.0001)$. Children in the intervention group received $95.5 \%$ of all recommended immunizations, compared with $87.2 \%$ in the control group $(p=0.044)$. 


\section{Web portals and health disparities}

This review also sought to explore disparities in patient web portal use. Irizarry et $\mathrm{al}^{2}$ conducted a systematic review of studies published from 2006 to 2014 about patient experiences with web portals and ways that patients may be supported to make competent health care decisions and act on those decisions using patient portal functionality. Of the eligible studies, four were cohort studies, fourteen were randomized controlled trials, and the remaining studies were descriptive, qualitative, pilot studies, or case reports. Studies identified in the review ${ }^{2}$ found that ethnic minorities (African American, Latino, Asian), younger persons, and patients who were less educated were less likely to adopt patient portals ${ }^{46,47}$ and that patients with chronic conditions and frequent users of health care services tended to be more interested in patient portals. ${ }^{4-51}$ Patients' interest in patient portals and ability to use them was found to be inversely related to the use of patient portals. ${ }^{52-54}$

The digital divide (population-level gaps in Internet and computer access) could limit access to web portals among disadvantaged groups. Roblin et a ${ }^{55}$ conducted a 2-year cohort study to assess racial/ethnic differences in rates of registration with personal health records among Kaiser Permanente Georgia enrollees. At baseline, 1,777 enrollees of age 25-59 years who had not registered with the personal health record were surveyed. Among African Americans, $30.1 \%$ registered, compared with $41.7 \%$ of whites $(p<0.01)$. Those with Internet access and higher education were more likely to register. Using data from the Kaiser Permanente Northern California Diabetes Registry, Sarkar et $\mathrm{al}^{6}$ examined the use of a patient web portal among adults with diabetes. Health literacy was measured using three validated self-report items. Among 14,102 participants (28\% non-Hispanic white, 14\% Latino, 21\% African American, 9\% Asian, 12\% Filipino, and 17\% multiracial or other ethnicity), 6,099 (62\%) reported some limitation in health literacy and 5,671 (40\%) respondents registered for the patient portal. Those with limited health literacy had a higher odds of not signing on to the patient portal (OR=1.7, 95\% CI 1.4-1.9), compared with those who did not report any health literacy limitation. The relationship between health literacy and patient portal use persisted among those with Internet access. Yamin et al ${ }^{56}$ conducted a cross-sectional analysis of a personal health record of a health system in northeastern USA (Partners HealthCare). Among 75,056 patients, 43\% had adopted the personal health record. Blacks and Hispanics were less likely to adopt the personal health record compared with whites (OR $=0.50,95 \%$ CI $0.45-0.55)$, and those with lower income were less likely to adopt the personal health record than those with higher income. To understand whether sociodemographic factors are related to patient portal use for secure messaging with providers, Graetz et $\mathrm{al}^{57}$ surveyed 1,041 patients with chronic conditions in a large integrated health care delivery system. Using one's own computer to access the Internet explained $52 \%$ of the association between race and secure message use and $60 \%$ of the association between income and secure message use $(p<0.001$ in each instance). Using administrative data and postal survey data, Gordon and Hornbrook ${ }^{58}$ examined differences in access to and preferences for using patient portals and other information technologies among older patients. The participants in the survey $(\mathrm{N}=314)$ were diverse by race/ethnicity. Adults aged 70-79 years were significantly less likely than 65-69 year olds to use the patient web portal to send messages, view lab test results, or request prescription refills. Non-Hispanic whites and Chinese patients were significantly more likely than Black, Latino, and Filipino patients to use the portal to send messages, view test results, or request prescription refills. Black, Latino, and Filipino seniors and those aged 75 years and older were significantly less likely to own computers or smartphones, or to use email than non-Hispanic whites, Chinese patients, and patients aged 65-69 years.

\section{Community web portals and health}

Web portals have also been used to address a variety of community environmental concerns such as housing, social connectivity, environmental exposures, and access to resources and facilities that promote health behaviors such as recreational facilities and farmers markets. ${ }^{59-62}$ Community web portals differ from patient web portals in that content and functionality are focused on community needs rather than specific patient needs. For example, government and municipal web portals often focus on promoting exchange of information and knowledge between community members to provide services, enhance community engagement, and encourage collective participation and decision making. ${ }^{63,64}$ In one recent example, the Healthy, Connected Chattanooga initiative, the city of Chattanooga, TN partnered with the Trust for Public Land to examine the opportunities for physical activity and to identify the areas where interventions were of highest need. ${ }^{61}$ Geographic information systems were used to analyze the city's existing park system which includes parkland owned by regional, state, and federal agencies. Locations that were not within a 10-minute walk of a park were identified as gaps. In addition, each park was scored based on demographic characteristics (percentage of 
population aged $\leq 19$ years, percentage aged $\geq 65$ years, percentage of low-income households, and population density), health indicators (obese or overweight adults, adults not meeting physical activity recommendations, and hospitalization rates for heart disease, diabetes, stroke, respiratory disease, and suicide), and indicators of recreational facility access. Planned interventions include the creation of new parks and the installation of free outdoor fitness facilities in existing parks. An online decision support tool (web portal) and maps are being used to make investment decisions. ${ }^{61}$

\section{Discussion}

The adoption of health information technologies such as electronic health records, personal health records, and patient web portals is widely viewed as vital to improving the quality and efficiency of health care systems and making health care more patient centered. An evidence base is accumulating from rigorous studies with historical cohorts (observational) or randomized controlled trial design on the effectiveness of patient web portals for improving health outcomes. ${ }^{12-15,18}$ Patient web portals have been shown to improve diabetes and hypertension disease management and increase adherence with screening recommendations. Yet, not all findings have been positive and the number of studies with a robust design is still modest.

Furthermore, despite increased interest among providers and researchers in patient web portals and increasing use of portals by patients, areas of resistance persist. Recent studies have shown that some providers have concerns about how patient web portals will affect their practice including potential added workload of facilitating patient use of portals or longer patient-physician interactions. ${ }^{65,66}$ There is also a potential for confusion and anxiety among patients who access their medical records online (e.g., radiology reports and sensitive laboratory test results). Psychiatric patients may be more likely to experience distress from accessing their personal health record ${ }^{67}$ In addition, administrative and logistical barriers may impede enrollment. ${ }^{65}$

Race/ethnicity, educational attainment, and health literacy have been linked to health disparities, ${ }^{68}$ and attention to the strong association between health literacy and patient portal use is needed to ensure patient portals do not worsen, but rather ameliorate health disparities. Potential solutions include avoiding or limiting medical jargon, using patientfriendly language, including links to explanations and definitions of terms, using illustrations, and using graphs to track trends in results such as blood pressure and blood glucose levels. ${ }^{2,53}$
In 2008, Google Inc. launched "Google Health", a free 24-hour web health portal aimed at empowering people to store their health records. Consumers showed little interest in such technology and it was soon abandoned. Identified barriers were privacy and security concerns and the intrinsic difficulties of transferring historical health records from hospitals and clinics to "Google Health". Many potential users of Google Inc. web solutions may not have completely understood the meaning and full potential value of a personal e-health record. Along with making integrated web health portals available, it is important to build in strategies to encourage initiation and interaction by users. In the past, technology such as automated telephone call centers were successful in the management of chronic diseases. ${ }^{69,70}$ This technology allowed for proactively reaching out to patients to encourage their engagement. Similar outreach efforts should be considered for patient web portals.

\section{Conclusion}

The majority of studies on the effectiveness of patient web portals have focused on portal use by patients with specific medical disorders such as diabetes, hypertension, and coronary heart disease and mental disorders. Additional studies are needed of the utility and effectiveness of web portals for other patient groups (e.g., patients with chronic respiratory, gastrointestinal, musculoskeletal, or dermatologic illnesses; women seen for obstetrical or gynecologic care; cancer patients and cancer survivors; patients followed for inheritable diseases such as sickle cell anemia). Also, greatly needed are studies of web portals for treating smoking and obesity. ${ }^{42}$ Community web portals and mHealth interventions for chronic disease risk factors in patient web portals have considerable potential for health promotion and patient education and warrant further evaluation.

\section{Disclosure}

The authors report no conflicts of interest in this work.

\section{References}

1. Sullivan D. Proven Portals: Best Practices for Planning, Designing, and Developing Enterprise Portals. 1st ed. Boston, MA: Pearson Education Inc; 2004

2. Irizarry T, Dabbs AD, Curran CR. Patient portals and patient engagement: a state of the science review. J Med Internet Res. 2015;17(6):e148.

3. Ammenwerth E, Schnell-Inderst P, Hoebst A. The impact of electronic patient portals on patient care: a systematic review of controlled trials. J Med Internet Res. 2012;14:e162.

4. Frost and Sullivan. Market disruption imminent as hospitals and physicians aggressively adopt patient portal technology. PR Newswire. Available from: http://www.prnewsire.com/news-releaases/marketdisruption-imminent-as-hospitals-and-physicians-aggressively-adoptpatient-portal-technology-225498752.html. Accessed January 1, 2017. 
5. Schnipper JL, Gandhi TK, Wald JS, et al. Effects of an online personal health record on medication accuracy and safety: a cluster-randomized trial. J Am Med Inform Assoc. 2012;19(5):728-734.

6. Sarkar U, Karter AJ, Liu JY. The literacy divide: health literacy and the use of an Internet-baed patient portal in an integrated health systemresults from the Diabetes Study of Northern California (DISTANCE). J Health Commun. 2010;15 (Suppl 2):183-196.

7. Mervak BM, Davenport MS, Flynt KA, et al. What the patient wants: an analysis of radiology-related inquiries from a web-based patient portal. J Am Coll Radiol. 2016;13(11):1311-1318.

8. Institute of Medicine Committee on Quality of Health Care in America. Crossing the quality chasm: a new health system for the 21 st century. Washington, DC: National Academy Press, 2001.

9. Ricciardi L, Mostashari F, Murphy J, et al. A national action plan to support consumer engagement via e-health. Health Aff (Millwood). 2013; 32(2):376-384.

10. Goldzweig CL, Orshansky G, Paige NM, et al. Electronic patient portals: evidence on health outcomes, satisfaction, efficiency, and attitudes. Ann Int Med. 2013;159(10):677-687.

11. Amante DJ, Hogan TP, Pagoto SL, English TM. A systematic review of electronic portal usage among patients with diabetes. Diabetes Technol Ther. 2014;16(11):784-793.

12. Wade-Vuturo A, Mayberry LS, Osborn CY. Secure messaging and diabetes management: experiences and perspectives of patient portal users. J Am Med Inform Assoc. 2013;20(3):519-525.

13. Shimada SL, Allison JJ, Rosen AK, et al. Sustained use of patient portal features and improvements in diabetes physiological measures. $J \mathrm{Med}$ Internet Res. 2016;18(7):e179.

14. Harris L, Haneuse SJ, Martin DP, Ralston JD. Diabetes quality of care and outpatient utilization associated with electronic patient-provider messaging: a cross-sectional analysis. Diabetes Care. 2009;32(7): 1182-1187.

15. Zhou YY, Kanter MH, Wang JJ, Garrido T. Improved quality at Kaiser Permanente through e-mail between physicians and patients. Health Aff (Millwood). 2010;29(7):1370-1375.

16. Tenforde M, Nowacki A, Jain A, Hickner J. The association between personal health record use and diabetes quality measures. $J$ Gen Intern Med. 2012;27(4):420-424.

17. Green BB, Cook AJ, Ralston JD, et al. Effectiveness of home blood pressure monitoring, web communication, and pharmacist care on hypertension control. A randomized controlled trial. JAMA. 2008; 299(24):2857-2867.

18. Harris L, Koepsell TD, Haneuse SJ, et al. Glycemic control associated with secure patient-provider messaging within a shared electronic medical record: a longitudinal analysis. Diabetes Care. 2013; 36(9):2726-2733.

19. Manard W, Scherrer JF, Salas J, Schneider FD. Patient portal use and blood pressure control in newly diagnosed hypertension. J Am Board Fam Med. 2016;29(4):452-459.

20. Ross SE, Moore LA, Earnest MA, et al. Providing a web-based online medical record with electronic communication capabilities to patients with congestive heart failure: randomized trial. $J$ Med Internet Res. 2004;6(2):e12.

21. McInnes K, D, Shimada SL, Rao SR, et al. Personal health record use and its association with antiretroviral adherence: survey and medical record data from 1871 US veterans infected with HIV. AIDS Behav. 2013; 17(9):3091-3100.

22. Simon GE, Ralston JD, Savarino J, et al. Randomized trial of depression follow-up care by online messaging. J Gen Intern Med. 2011;26(7): 698-704.

23. Wagner PJ, Dias J, Howard S, et al. Personal health records and hypertension control: a randomized trial. J Am Med Inform Assoc. 2012;19(4): 626-634.

24. Kipping S, Stuckey MI, Hernandez A, et al. A web-based patient portal for mental health care: benefits evaluation. J Med Int Res. 2016; 18(11):e294
25. Grant RW, Wald JS, Schnipper JL, et al. Practice-linked online personal health records for type 2 diabetes mellitus. A randomized controlled trial. Arch Intern Med. 2008;168(16):1776-1782.

26. Ralston JD, Hirsch IB, Hoath J, Mullen M, Cheadle A, Goldberg HI. Web-based collaborative care for type 2 diabetes: a pilot randomized trial. Diabetes Care. 2009;32(2):234-239.

27. McCarrier KP, Ralston JD, Hirsch IB, et al. Web-based collaborative care for type 1 diabetes: a pilot randomized trial. Diabetes Technol Ther. 2009;11(4):211-217.

28. Tang PC, Overhage JM, Chan AS, et al. Online disease management of diabetes: engaging and motivating patients online with enhanced resources-diabetes (EMPOWER-D), a randomized controlled trial. $J$ Am Med Inform Assoc. 2013;20(3):526-534.

29. Lau M, Campbell H, Tang T, et al. Impact of patient use of an online patient portal on diabetes outcomes. Can J Diabetes. 2014;38(1):17-21.

30. Kopanitsa G, Karpov A, Lakovenko G, Laskovenko A. Implementation of a web portal for diabetes patients using open source data visualization libraries. Stud Health Technol Inform. 2016;224:189-194.

31. Tutino GE, Yang WY, Li WH, et al. A multicenter demonstration project to evaluate the effectiveness and acceptability of the web-based Joint Asia Diabetes Evaluation (JADE) programme with or without nurse support in Chinese patients with Type 2 diabetes. Diabet Med. In press 2016.

32. Talboom-Kamp EP, Verdijk NA, Blom CM, et al. e-Vita: design of an innovative approach to COPD disease management in primary care through e-Health application. BMC Pulm Med. 2016;16(1):122.

33. Ahmed S, Ernst P, Bartlett SJ, et al. The effectiveness of web-based asthma self-management system, my asthma portal (MAP): a pilot randomized controlled trial. J Med Int Res. 2016;18(12):e313.

34. Wiljer D, Leonard KJ, Urowitz S, et al. The anxious wait: assessing the impact of patient accessible EHRs for breast cancer patients. BMC Med Inform Decis Mak. 2010;10:46.

35. Epstein JN, Kelleher KJ, Baum R, et al. Impact of a web-portal intervention on community ADHD care and outcomes. Pediatrics. 2016; 138(2):e20154240.

36. Koivunen M, Valimaki M, Pitkanen A, Kuosmanen L. A preliminary usability evaluation of web-based portal application for patients with schizophrenia. J Psychiatr Ment Health Nurs. 2007;14(5):462-469.

37. Bourgeois FC, Mandl KD, Shaw D, et al. Mychildren's: integration of a personally controlled health record with a tethered patient portal for a pediatric and adolescent population. AMIA Annu Symp Proc. 2009;2009:65-69.

38. Byczkowski TL, Munafo JK, Britto MT. Family perceptions of the usability and value of chronic disease web-based patient portals. Health Informatics $J$. 2014;20(2):151-162.

39. Megan Forster M, Dennison K, Callen J, et al. Maternity patients' access to their electronic medical records: use and perspectives of patient portal. HIM J. 2015;44(1):4-11.

40. Tuil WS, Verhaak CM, Braat DDM, et al. Empowering patients undergoing in vitro fertilization by providing Internet access to medical data. Fertil Steril. 2007;88(2):361-368.

41. Barbara AM, Dobbins M, Haynes RB, et al. The McMaster Optimal Aging Portal: usability evaluation of a unique evidence-based health information website. JMIR Hum Factors. 2016;3(1):e14.

42. Krist AH, Woolf SH, Rothemich SF, et al. Interactive preventive health record to enhance delivery of recommended care: a randomized trial. Ann Fam Med. 2012;10(4):312-319.

43. Wright A, Poon EG, Wald J, et al. Randomized controlled trial of health maintenance reminders provided directly to patients through an electronic PHR. J Gen Intern Med. 2011;27(1):85-92.

44. Henry SL, Shen E, Ahuja A, et al. The online personal action plan: a tool to transform patient-enabled preventive and chronic care. Am J Prev Med. 2016;51(1):71-77.

45. Nagykaldi Z, Aspy CB, Chou A, Mold JW. Impact of a wellness portal on the delivery of patient-centered preventive care. J Am Board Fam Med. 25(2):158-167. 
46. Lober WB, Zierler B, Herbaugh A, et al. Barriers to the use of a personal health record by an elderly population. AMIA Annu Symp Proc. 2006:514-518. Available from: http://europepme.org/abstract/ MED/17238394. Accessed January 1, 2017.

47. Lafky DB, Horan TA. Prospective personal health record use among different user groups: results of a multi-wave stud. Proceedings of the 41st Annual Hawaii International Conference on System Sciences; January 7-10; 2008; Honolulu, HI, USA.

48. Goel MS, Brown TL, Adam W, et al. Patient reported barrires to enrolling in a patient portal. $J$ Am Med Inform Assoc. 2011;18 (Suppl 1): i8-i12.

49. Sanders MR, Winters $P$, Fortuna RJ, et al. Internet access and patient portal readiness among patients in a group of inner-city safety-net practices. J Ambul Care Manage. 2013;36(3):251-259.

50. Krist AH, Woolf SH, Bello GA, et al. Engaging primary care patients to use a patient-centered personal health record. Ann Fam Med. 2014;12(5):418-426.

51. Taha J, Czaja SJ, Sharit J, et al. Factors affecting usage of a personal health record (PHR) to manage health. Psychol Aging. 2013;28(4):1124-1139.

52. Noblin AM, Wan TTH, Fottler M. The impact of health literacy on a patient's decision to adopt a personal health record. Perspect Health Inf Manag. 2012;9:1-13.

53. Haggstrom DA, Saleem JJ, Russ AL, et al. Lessons learned from usability testing of the VA's personal health record. J Am Med Inform Assoc. 2011;18 (Suppl 1):i13-i17.

54. Monkman H, Kushniruk A. Applying usability methods to identify health literacy issues: an example using a personal health record. Stud Health Technol Inform. 2013;183:179-185.

55. Roblin DW, Houston TK, Allison JJ, et al. Disparities in use of a personal health record in a managed care organization. J Am Med Inform Assoc. 2009;16(5):683-689.

56. Yamin CK, Emani S, Williams DH, et al. The digital divide in adoption and use of a personal health record. Arch Intern Med. 2011;171(6): 568-574.

57. Graetz I, Gordon N, Fung V, et al. The digital divide and patient portals: internet access explained differences in patient portal use for secure messaging by age, race, and income. Med Care. 2016;54(8): $772-779$.
58. Gordon NP, Hornbrook MC. Differences in access to and preferences for using patient portals and other eHealth technologies based on race, ethnicity, and age: a database and survey study of seniors in a large health plan. J Med Internet Res. 2016;18(3):e50.

59. Jordan M, DuClos C, Folsom J, Thomas R. Development a smartphone interface for the Florida environmental public health tracking web portal. J Public Health Manage Pract. 2015;2021 (Suppl 2):S504.

60. Brown EM, Van Dyke M, Kuhn S, et al. Private well water in Colorado: collaboration, data use, and public health outreach. J Public Health Manag Pract. 2015; 21 (Suppl 2):S85-S92.

61. Elwell H, Shulaker B, Rippon J, Wood R. Strategic and integrated planning for healthy, connected cities: Chattanooga case study. Prev Med. In press 2016.

62. Little KE, Hayashi M, Liang S. Community-based groundwater monitoring network using a citizen-science approach. Ground Water. 2016; 54(3):317-324.

63. Detlor B, Hupfer ME, Ruhi U, Zhao L. Information quality and community municipal portal use. Gov Inform Quart. 2013;30(1):23-32.

64. Sandoval-Almazan R, Gil-Garcia JR. Are government internet portals evolving towards more interaction, participation, and collaboration? Revisiting the rhetoric of e-government among municipalities. Gov Inform Quart .2012;29:S72-S81.

65. Fix GM, Hogan TP, Amante DJ, et al. Encouraging patient portal use in the patient-centered medical home: three stakeholder perspectives. J Med Int Res. 2016;18(11):e308.

66. Lee CI, Langlotz CP, Elmore JG. Implications of direct patient online access to radiology reports through patient web portals. J Am Coll Radiol. 2016;13(12 Pt B):1608-1614.

67. Ross SE, Lin C-T. The effects of promoting patient access to medical records: a review. J Am Med Inform Assoc. 2003;10:129-138.

68. Institute of Medicine. Unequal Treatment: Confronting Racial and Ethnic Disparities in Health Care. Washington, DC: National Academy Press; 2002.

69. Boren SA, De Leo G, Chanetsa FF, et al. Evaluation of a diabetes education call center intervention. Telemed JE Health. 2006;12(4):457-465.

70. De Leo G, Krishna S, Boren S, et al. Web and computer telephone-based diabetes education: lessons learned from the development and use of a call center. J Med Syst. 2005;29(4):343-355.
Risk Management and Healthcare Policy

\section{Publish your work in this journal}

Risk Management and Healthcare Policy is an international, peer-reviewed open access journal focusing on all aspects of public health, policy, and preventative measures to promote good health and improve morbidity and mortality in the population. The journal welcomes submitted papers covering original research, basic science, clinical and epidemiological

\section{Dovepress}

studies, reviews and evaluations, guidelines, expert opinion and commentary, case reports and extended reports. The manuscript management system is completely online and includes a very quick and fair peerreview system, which is all easy to use. Visit http://www.dovepress.com/ testimonials.php to read real quotes from published authors. 